\title{
Cuidar do cuidador: transbordamento e carência
}

Ligia Py

Pesquisadora do Núdeo de Estudos e Pesquisas em Tanatologia do Instituto de Psicologia/UFRJ. E-mail: ligiapy@ matrix.com.br

\begin{abstract}
Resumo
Este texto é produto de uma comunicação realizada na Jornada de Bioética promovida pelo Conselho de Bioética do IN CA, no dia 06 de julho de 2004. Trata de dificuldades emocionais de familiares cuidadores de pacientes com câncer, carentes eles mesmos de cuidados especiais. Lembra que, na grande maioria das vezes, a mulher é protagonista do cuidado. Partindo de um convite à reflexão dos profissionais, considera a sua responsabilidade por esse cuidado, no campo de trabalho que lida com a situação de seres humanos que criam uma dependência gradativa, podendo chegar à dependência integral, no percurso inexorável de uma doença incurável, com piora progressiva, aproximandose da morte. Alerta para a necessidade de uma formação profissional peculiar, fundamentada na práxis ontocriativa, propondo a inclusão de um trabalho reflexivo e vivencial, integrado ao exercício contínuo de capacitação teóricoprática. $\mathrm{Na}$ abordagem da dinâmica da relação paciente-familiar cuidador, chama a atenção para o fato de que também esse cuidador, quase sempre mulher, se implica numa forma de dependência, na dinâmica do cuidado que presta ao paciente. Ressalta possibilidades de construção da interdependência solidária nessa relação. A argumentação baseia-se em recursos conceituais referentes à vivência do desamparo e à ambivalência de sentimentos vividos no par amor e ódio, que domina a relação paciente-familiar cuidador. Concluindo, aponta para possibilidades de reconstrução contínua dessa relação de dependência quando gestada em figurações do ódio, para um estilo de relação de interdependência solidária, como proposta libertadora.
\end{abstract}

\section{Introdução}

A primeira experiência radical do ser humano é o nascer. A outra é o morrer.

0 nascimento de uma criança tem significações de alegria e esperança, na renovação da vida. A celebração do $\mathrm{N}$ atal continua comovendo o mundo inteiro, imerso na barbárie que se adensa e aprofunda. Entre nós, brasileiros, a radicalidade de "M orte e Vida Severina" insiste em nos lembrar o nascimento do filho, na miséria, embora, superando a decisão desesperada da morte do pai.

Percorrer os caminhos de uma doença incurável, com piora progressiva até a morte, nos cânones de uma sociedade que valoriza o vigor e a beleza, a produção e o consumo, exige do ser humano formas de superações sucessivas, difíceis de alcançar, na sua condição de doente, dependente, carente, diferente, ele mesmo, tornado ente supremo de um saber sobre a vida que se acaba. A chegada da morte, com implicações gestadas no medo, na recusa, na negação, nos sentimentos de fracasso, ameaça e culpa, deve ser considerada como a solenidade final de uma existência. Vemos em M auksch ${ }^{1}$ que "morrer é uma experiência total e na hora de morrer o órgão afetado deixa de ser o item básico."

Cuidar de bebês que nos anunciam a vida e a esperança, tanto quanto cuidar de pessoas doentes que nos anunciam o sofrimento e a morte, é um privilégio. Podemos dizer que 'no princípio era' o cuidado, que viabilizou a vida neste planeta, pela aproximação dos homens na defesa contra os perigos e na gênese das descobertas que continuam... como nos fala B off², inspirado, também, na concepção freudiana de desamparo.

D entre a multiplicidade de questões que se apresentam no cuidado com os cuidadores, destacamos, para este trabalho: um convite aos profissionais desse campo a uma reflexão sobre a sua própria finitude, para, então, tratarem das possibilidades de os familiares que cuidam dos seus, se entenderem numa relação de dependência, vivendo o desamparo, 0 amor e o ódio; a reafirmação de que as mulheres aparecem em esmagadora maioria como protagonistas no ato de cuidar; a proposta de chegarmos à interdependência solidária que pode libertar todos os 
membros da relação de cuidado, para fazêlos alcançar a condição de dignidade humana que tanto almejamos, em quaisquer circunstâncias.

\section{Um Convite à R eflexão}

0 andróide do filme "Blade Runner", na cena final, provoca, no seu caçador humano, uma perplexidade que 0 conduz a reflexões acerca da vida e da morte, suscitando a interpelação sobre a nossa propalada humanidade: "queria as mesmas respostas: - de onde venho? - para onde vou? - quanto tempo tenho? ... talvez, naqueles últimos momentos, ele amasse a vida mais do que havia amado antes; não somente a vida dele, mas a vida de qualquer um, a minha vida ... e tudo o que eu posso fazer é ficar aqui e vêlo morrer."

Provocados por essa cena, pensamos a nossa própria finitude, a angústia de nos sabermos inexoravelmente mortais, radicalmente ignorantes sobre o destino da nossa vida humana e mortal, inapelavelmente transitória, cujos tempos passado e presente a projetam a um futuro, na permanência desejante de satisfação. Pensamos as possibilidades do outro, morrendo, despedindo-se da vida, fechando o último capítulo da sua história pessoal para inscrevêlo na história da coletividade humana ${ }^{3}$. N esse momento derradeiro, assoma à saída da vida, com o transbordamento da sua potencialidade toda, podendo, agora, sim, considerar o vivo, expandido na sua capacidade amorosa para a real valorização de tudo o que é vivo e, mortal, embora, permanece para, quem sabe, completar o inacabamento da sua própria vida.

A busca da competência profissional é, na verdade, uma condução ética, a partir da humildade que funda a ousadia de um fazer compartilhado, solidário e transformador, na relação profissionais-pacientes-familiares. N ão trabalhamos sozinhos. Estamos, sempre, engajados em equipes profissionais que devemos tornar grupos.

A forma privilegiada de trabal har em grupo é apresentada por $M$ inayo ${ }^{4}$ e Bleger ${ }^{5}$, onde a estrutura e a dinâmica do grupo, não só se abrem ao acolhimento de demandas, à reflexão crítica e à produção de ações transformadoras, como também favorecem pensá-lo como um grupo social constituído por pessoas que estabelecem uma intercomunicação sobre as situações específicas que as atingem coletivamente; a partir daí, é possível se desenvolverem modos de pensar abrangentes que se integram na compreensão e nas ações de cada um dos membros do grupo.

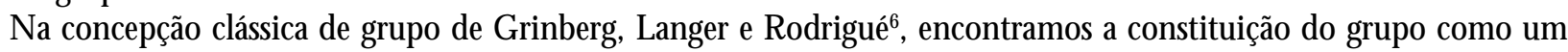
conjunto de pessoas que compartilham normas comuns e desempenham papéis sociais interligados, formando uma totalidade. 0 trabalho desenvolvido pelo grupo implica num sistema dinâmico, no qual cada membro, com o seu papel individual, depende dos demais. O ra, para a nossa reflexão aqui, essa concepção é particularmente interessante, pois temos configurado a interdependência, onde cada um dos membros atua em função dos demais. A interação dos participantes de um grupo acontece como figura sobre um fundo que agrega todos, indiscriminada e sincreticamente, constituindo "o vínculo mais poderoso entre os membros do grupo... o fundo de solidariedade ... ${ }^{\prime \prime}$

É desse modo que podemos estar disponibilizados para a entrega a uma reflexão sobre a nossa própria vida, as possibilidades de adoecermos, a nossa mortalidade. D essa reflexão, podemos sair fortalecidos para adentrarmos a cena da doença, do sofrimento, da dependência e da morte do outro. Até porque, sentimos que os familiares de quem vamos também cuidar, precisam, sim, de informação e instrumentalização para cuidar do paciente, contudo, carecem profundamente de uma reflexão sobre a situação em que se encontram, para a qual precisam criar viabilidades no contexto familiar. Podemos buscar a orientação da lógica dialética que, no dizer de Bleger ${ }^{5}$, compreende conteúdos de interação entre a teoria e a prática, perpassados pela singularidade do modo peculiar de cada profissional administrar os próprios recursos internos que vão compor a ação de intervir.

Estamos participando do processo de adoecer e morrer de seres humanos cuidados por seus familiares, onde pacientes e cuidadores são, a um só tempo, sujeito e objetos da nossa intervenção. $E$ nós, profissionais, também adoecemos e somos igualmente mortais. Por isso, recorremos a Kosik ${ }^{7}$, que nos ensina o processo ontocriativo da práxis, fundante das possibilidades de compreensão do ser humano, a partir da compreensão de cada um acerca de si mesmo.

A experiência do convívio com os pacientes no fim da vida, cuidados pelos seus familiares, é provocadora da reflexão sobre a 'realização da liberdade humana'7. Será esse o insight que vai iluminar as produções do nosso trabalho? No texto de O liveira ${ }^{8}$, aprendemos:

"Encontrar possibilidades de humanização do humano entre os humanos é uma andança cheia de aventuras, tropeços, idas-e-vindas, indignação, alegria, desalentos, êxitos, consolo, tensão, derrotas e incertezas. Supõe, por isso mesmo, um esforço infinito por energias sempre multiplicadas, esforço partilhado por outros numa comunhão em luta, sem fim." 
Assim é que a nossa proposta se configura na inserção de um trabalho sistemático, vivencial e reflexivo, na formação continuada dos profissionais que lidam com a aproximação da morte de pessoas com câncer, carentes de cuidados profissionais e familiares. Cremos que a formação centrada em trabalho teórico-vivencial atende às características da prática profissional, subvertendo positivamente os critérios convencionais, desconstruindo uma praxe desvitalizada e instaurando a práxis ontocriativa, na verdade o modus operandi por excelência do cuidado ao fim da vida dos seres humanos.

\section{Relação de Cuidado e (Inter)D ependência}

Trabalhamos a conceituação de cuidado referida ao discurso da Enfermagem, num outro estudo ${ }^{9}$, ressaltando a primazia dessa categoria na prática de cuidar. Encontramos no texto de Gonçalves e Alvarez ${ }^{10}$, a humanidade assegurando a preservação da espécie e da vida do grupo, desde os primórdios da sua existência, valendo-se da ação do cuidado, um 'tomar conta' do sustento alimentar, da procriação e criação da prole, da proteção e defesa da habitação e do território. N esse sentido, Freud, em "O futuro de uma ilusão"11, pensa a civilização, como 0 resultado da reunião dos humanos, não só para aquisições novas e arrojado sentido de ir adiante, mas, basicamente, para se defenderem dos perigos das forças da natureza. Aí se revela o desamparo do ser humano, experiência que vai revivendo ao longo da vida, desde o nascimento.

Um recém-nascido precisa ser cuidado, condição sine qua non da sua existência. Em "Inibições, sintomas e ansiedade" ${ }^{12}$, Freud nos fala da prematuração do ser humano ao nascer que, diferente da maioria dos animais, chega ao mundo com a necessidade radical de ser cuidado. Ao longo da vida, a cada vez que o ser humano se depara com uma situação de perigo, Ihe sobrevém o desamparo, demandando um pedido de ajuda.

Pelas limitações trazidas pela doença, pessoas que adoecem de câncer, progressivamente se tornam dependentes de cuidado integral, até a morte. Q uem assume o cuidado são os familiares, predominantemente mulheres, assim como acontece em qualquer outra situação de prestação de cuidado na esfera familiar, quando se trata da saúde de um dos seus.

Tratando dos novos contratos intergeracionais e de gênero da época atual, Goldani ${ }^{13}$ nos fala da mulher como protagonista do cuidado aos pais e parentes idosos, doentes. É a mulher que vai priorizar a dedicação ao cuidar, em detrimento do lazer, da socialização e até das atividades profissionais, com prejuízos, por vezes fatais, no desempenho e na permanência no emprego.

$\mathrm{N}$ a visão de $\mathrm{N} \mathrm{eri}^{14}$, na vida contemporânea, há dificuldades para o aprofundamento dos laços de afeição, da busca do significado existencial, da reflexão sobre o sentido da velhice e da morte. Esses fatores, aos quais se inclui a carência de ajuda sistemática formal aos familiares, são coadjuvantes da significação negativa que assume a ação de cuidar, quando se trata de dependência. No entanto, chama-nos a atenção o posicionamento firme e crítico dessa pesquisadora, na recusa à aceitação do cuidar, exclusivamente como uma situação deletéria para a pessoa cuidadora, apontando para a realidade de experiências positivas na relação do cuidado, com indicadores de crescimento pessoal de quem cuida.

0 trabalho profissional com os familiares cuidadores contempla uma dupla vertente: informação e reflexão. D esse modo, estamos atendendo à nossa proposta de estar trabalhando na práxis ontocriativa, que integra os momentos laborativo e existencial, através da operacionalidade do fazer e da imersão no pensar sobre o fazer ${ }^{7}$. Cremos ser necessário instruir os familiares nas especificidades da prática do cuidado, assim como cremos ser necessário atentar para os sentimentos que emergem na lida diária com a pessoa doente. A reflexão é uma proposta, um convite para os familiares cuidadores se pensarem na relação de dependência e cuidado, na aproximação da morte, o que os leva a também se pensarem na perspectiva das suas possibilidades pessoais de adoecimento e na sua própria finitude. D essa mesma forma trabalhamos com os profissionais, para que sejam capazes de cuidar dos cuidadores, como expressamos acima. 0 caráter transformador, esperado nessa dinâmica, está na possibilidade de articulação dos conteúdos objetivados na informação, com a capacidade de subjetivação do familiar cuidador. A relação de cuidado é marcada por perplexidades e dúvidas, que orientam a busca da solidariedade e da libertação. $N$ esse percurso, os familiares cuidadores confrontam sentimentos de amor e ódio, como, por exemplo, o nojo e o cuidado com o corpo, a onipotência e a capacidade de compartilhar. São pares de opostos, como os descritos por Freud em "Sadismo e masoquismo"15, que apontam para 0 dualismo fundamental, exigência teórica para a tradução do conflito. A radicalização desses sentimentos expressa-se criativa, dialética e libertariamente, nas falas dos familiares cuidadores, quando encontram a nossa escuta compreensiva.

É importante lembrarmos que não há naturalidade no amor. N em no ódio. Somos habitados por ambos, gestados nas relações humanas que construímos e que, afinal, nos constroem. Se existe, o amor impele ao cuidado. Se for o ódio que impera, não basta reconhecêlo no contexto do cuidado. É preciso que haja um redirecionamento das 
ações do cuidar, de modo que aquele que cuida possa exercer um controle sobre a realidade da dominação, da tirania e do julgamento a que procedem. ${ }^{16}$

0 nojo é uma figuração do ódio. Esse sentimento, que se manifesta na intolerância e na rejeição, pode estar fazendo parte, também, do cuidado dispensado ao paciente, como expressão do repúdio a uma situação que se torna insuportável. Por exemplo, uma esposa amorosa debate-se no amor e no ódio, em ebulição simultânea, na relação com o marido doente, o corpo deformado, aproximando-se da morte. 0 nojo a invade, a revolve internamente, a impele à rejeição, sem que ela alcance a dimensão do que lhe acontece. A repulsa ao corpo que inspira nojo a conduz à ação de expulsar, repelir. ${ }^{17}$

A leitura de Freud em "A perda da realidade na neurose e na psicose"18 nos leva a pensar nesse nojo como um sentimento que está mediando a separação, já de al guma forma instalada, anunciando a morte chegando, implacável, definitiva. Prenúncio da morte de um corpo sob seus cuidados que, outrora, representou, para ela, o corpo objeto do desejo.

D espedir-se desse corpo, num trabalho de luto antecipado ${ }^{19}$, pode reinaugurá-la na relação de cuidado, valendo-se da 'morte com aviso prévio' para o trabalho psíquico da história das emoções presentes no vínculo amoroso e toda forma de repúdio sentido agora, com a mediação do cuidado com esse corpo que prescreve uma ação de despedida. ${ }^{20}$ U ma outra figuração do ódio é a onipotência que submete e domina. Tomar a si a responsabilidade e a competência, exclusivas e excludentes, para cuidar do outro, fragilizado e vulnerável é colocar-se no lugar da onipotência. A sustentação desse lugar é uma produção a dois: do familiar cuidador e do paciente. $\mathrm{N}$ a onipotência, aquele que cuida crê ser possuidor do deciframento das carências do outro. Crê ser inteiramente capaz da competência de cuidar. É assim que, sem ter consciência do que está acontecendo, o familiar cuidador se autoriza a exercer um domínio que submete, que viabiliza 0 abandono do paciente aos seus cuidados. ${ }^{21}$

O s sentimentos solidários dos familiares cuidadores podem opor-se à onipotência de um só, gerando um movimento expansivo na generosidade que sustenta a capacidade de compartilhar. Assim, a saída do lugar de onipotência pressupõe a abertura da relação: incluir outros familiares no cotidiano dos cuidados é um modo de fazer 0 cuidador e o paciente 'se perderem' para 'se ganharem' num outro patamar. Ambos se complementam na liberação do fardo que os aprisionava na carência de um (o paciente) e na abdicação do outro (o familiar cuidador). Libertos, podem, agora, reinaugurar-se na relação de interdependência, engendrada pela solidariedade.

\section{C onsiderações Finais}

No decorrer do nosso trabalho, sentimos que o contato direto com os familiares cuidadores de pessoas com câncer, aproximando-se da morte, confronta a nossa própria vida, o nossa próprio processo saúde-doença, a nossa própria morte. $\mathrm{N}$ ós, seres ontocriativos ${ }^{7}$, compartilhamos sentimentos abissais, nos transformando à medida que provocamos o outro se transformar e, por isso mesmo, nos é revelado um sentido para viver o sofrimento; sentido como significado e destinação. ${ }^{22} \mathrm{~A}$ compreensão de Pessini ${ }^{23}$ alcança as origens dessas preocupações:

"O sofrimento também nos infunde 'medo', porque nos vemos em espelho, a fragilidade, a vulnerabilidade

e a mortalidade, elementos da nossa condição humana que não gostamos de ver lembrados... porque nos

confrontam com o nosso próprio fim."

Aqui, assim como no estudo que realizamos sobre pessoas idosas doentes e seus familiares cuidadores, ${ }^{9}$ insistentemente nos indagamos: - Q ue idéias inconscientes subjazem aos sentimentos de nojo e onipotência? $\mathrm{Na}$ relação pacientefamiliar cuidador existe um transbordamento dos afetos por aquilo que se faz insuportável, no transcurso da doença. No texto de Freud "Emoções inconscientes" ${ }^{24}$, vemos que cada afeto está ligado a uma idéia que é o seu representante no inconsciente. Uma idéia detestável, aquilo que é insuportável na relação com o outro, quando ultrapassa o limite da sua força, faz com que o conflito se torne real. Então, desde muito cedo, os seres humanos se debatem entre exigências internas contrárias. $E$ as idéias persistem, nas suas vicissitudes, particularmente ligadas aos processos de repressão, que formam substitutos ou sintomas. Persistem as idéias, na sua tarefa contínua de vincular-se aos traços da memória, ou seja, aos conteúdos da história dos sujeitos. E os afetos? São manifestações das idéias, são tudo aquilo que percebemos como nossos sentimentos.

A existência do ódio manifesta-se em diferentes figurações, engendrado na intimidade das idéias que constituem a história de cada um. Esse ódio, porém pode liberar-se para estar a serviço do sentimento amoroso, na ação solidária de cuidar do outro.

Referências

1. M auksch H . O contexto organizacional do morrer. In: Kübler-Ross E, organizer. M orte: estágio final da evolução. Rio de Janeiro: Record; 1975. p. 33-52. 
2. Boff L. Saber cuidar. Ética do humano: compaixão pela terra. 6a ed. Petrópolis: Vozes; 1999.

3. Daniel H. Anotações à margem do viver com AIDS. In: Lancetti A. Saúdeloucura, número 3. São Paulo: HICITEC; 1991. p. 3-20. (Saúde em debate).

4. M inayo M CS. O desafio do conhecimento: pesquisa qualitativa em saúde. 3a ed. São Paulo: H U CIT EC; Rio de Janeiro: ABRASC 0; 1994.

5. Bleger J. Temas de psicologia: entrevista e grupos. São Paulo: M artins Fontes; 1980.

6. Grinberg L, Langer $M$, Rodrigué $E$. Psicoterapia de grupo: enfoque psicanalítico. Rio de Janeiro: Forense Universitária; 1976.

7. Kosik K. Dialética do concreto. 2a ed. Rio de Janeiro: Paz e Terra; 1976.

8. OliveiraP deS. Vidas compartilhadas: cultura eco-educação de gerações na vida cotidiana. São Paulo: H U CITEC/ FAPESP; 1999.

9. Py L. Velhice nos arredores da morte: a interdependência entre idosos e seus familiares. Porto Alegre: ED IPU CRS; 2004.

10. Gonçalves LH T, Alvarez AM . 0 cuidado na enfermagem gerontogeriátrica: conceito e prática. In: Freitas EV, orgaizadora. Tratado de geriatria e gerontologia. Rio de Janeiro: Guanabara Koogan; 2002. p. 756-61.

11. Freud S. 0 futuro de uma ilusão. In: 0 bras psicológicas completas de Sigmund Freud. Tradução de Jayme Salomão. Rio de Janeiro: Imago; 1980. p. 15-80. (Edição Standard Brasileira; vol. 21).

12. Freud S. Inibições, sintomas e ansiedade. In: O bras psicológicas completas de Sigmund Freud. Tradução de Jayme Salomão. Rio de Janeiro: Imago; 1980. p. 107-98. (Edição Standard Brasileira; vol. 20).

13. Goldani AM. Mulheres e envelhecimento: desafios para novos contratos intergeracionais e de gênero. In: Camarano AA, organizador. Muito além dos 60: os novos idosos brasileiros. Rio de Janeiro: IPEA; 1999. p. 75-113.

14. Neri AL, organizador. Cuidar de idosos no contexto da família: questões psicológicas e sociais. Campinas: Alínea; 2001.

15. Freud S. Sadismo e masoquismo.Três ensaios sobre a teoria da sexualidade. In: 0 bras psicológicas completas de Sigmund Freud. Tradução de Jayme Salomão. Rio de Janeiro: Imago; 1980. p. 159-62. (Edição Standard Brasileira; vol. 7).

16. Py L, Scharfstein EA. Caminhos da maturidade: representações do corpo, vivências dos afetos e consciência da finitude. In: N eri AL, orgaizador. M aturidade e velhice: trajetórias individuais e socioculturais. Campinas: Papirus; 2001. p. 117-50.

17. Laplanche J, Pontalis JB. Vocabulário de psicanálise. 4a ed. São Paulo: M artins Fontes; 2001.

18. Freud S. A perda da realidade na neurose e na psicose. 0 ego e 0 id. In: 0 bras psicológicas completas de Sigmund Freud. Tradução de Jayme Salomão. Rio de Janeiro: Imago; 1980. p. 229-38. (Edição Standard Brasileira; vol. 19).

19. Torres WC. As perdas do paciente terminal e o luto antecipado. Psicol Argum. 2000;19(28):7-12.

20. Doll J. Luto e viuvez na velhice. In: Freitas EV, organizadora. Tratado de geriatria e gerontologia. Rio de Janeiro: Guanabara Koogan; 2002. p. 999-1012.

21. Sathler J, Py L. Pensando perdas e aquisições no processo de envelhecer: o trabalho psíquico. In: SBGG (RJ). Caminhos do envelhecer. Rio de Janeiro: Revinter; 1994. p. 15-7.

22. Green A. N arcisismo de vida, narcisismo de morte. São Paulo: Escuta; 1998.

23. Pessini L. M orrer com dignidade: até quando manter a vida artificialmente? Aparecida (SP): Santuário;1990.

24. Freud S. Emoções inconscientes. $O$ inconsciente. In: $O$ bras psicológicas completas de Sigmund Freud. Tradução de Jayme Salomão. Rio de Janeiro: Imago; 1980. p. 203-6. (Edição Standard Brasileira; vol. 14). 